\title{
THE WATER COOLING SYSTEM IN THE POOL OF THE DGKN-120 HYPERBARIC SIMULATOR CHAMBER
}

\section{Zbigniew Talaśka}

Naval Academy, Department of Underwater Works Technology in Gdynia, Poland

\section{ABSTRACT}

This article presents a description of the water cooling system in the pool of the "Kobuz" decompression chamber constituting a part of the DGKN-120 hyperbaric simulator used at the Department of Underwater Works Technologies of the Naval Academy in Gdynia. Keywords: hyperbaric chambers, diving simulators, equipment of hyperbaric chambers.

ARTICLE INFO

PolHypRes 2018 Vol. 63 Issue 2 pp. 7 - 20

ISSN: $1734-7009$ eISSN: 2084-0535

DOI: $10.2478 / \mathrm{phr}-2018-0008$

Pages: 14, figures: 8 , tables: 3

page www of the periodical: www.phr.net.pl

Publisher

Polish Hyperbaric Medicine and Technology Society
Original article

Submission date: $19.04 .2018 \mathrm{r}$. Acceptance for print: 15.05.2018 r. 


\section{INTRODUCTION}

The water-cooling system in the "Kobuz" decompression chamber, a part of the DGKN-120 hyperbaric simulator, allows for temperature changes under water depending on the needs of any given simulated diving exposure. Low water temperatures are particularly important in experimental research and tests. During these simulated dives, it is possible to determine the effects of the cold on the diver's organism as well as the diver's efficiency in cold water. The research also subjected to analysis the diver's personal and respiratory equipment, including the susceptibility to the freezing effect of its components that have a direct impact on human health and life. The provision of a new cooling system in the simulator extends the research capabilities of the hyperbaric simulator, increases the range of pressure training in different underwater conditions and allows for the implementation of a number of other projects where it is necessary to simulate low temperature water environments.

\section{LOW TEMPERATURE IN DIVING REALATED}

\section{ISSUES}

Temperature is one of the basic yet important parameters occurring within diving-related issues. The impact of the aquatic environment on the human body, including especially its changes, have a direct impact on the course of each diving exposure. This results from, amongst other things, the construction of the human body, its physiology, maintaining the conditions of homeostasis and a range of other mechanisms. In general, the problems associated with the impact of temperature on the diver's stay under water can be divided into two spheres:
a) medical, and
b) technical.

\section{THE EFFECT OF A HYPERBARIC ENVIRONMENT ON DIVER'S ORGANISM}

In normobaric conditions, the human body is homothermal. An important element of its functioning, aimed at maintaining, among others, the body temperature, are the metabolic processes, i.e. metabolism. Energy is released as a result of the burning of consumed foods. One of the important products of this process is heat. The metabolism itself requires the action of specific enzymes whose activity is a function of the temperature generated in the tissues [1]. In the event of the work of these enzymes being disrupted, a disturbance of the metabolic process occurs, and as a result the body temperature stability changes.

The value of the temperature inside the core of the body, at which the vital processes are unimpeded is equal to about $37^{\circ} \mathrm{C}$ and is practically constant [2] with the assumption of stable external conditions. This condition is primarily influenced by the thermoregulatory capabilities of the body. However, the temperature of the outer layer of the body, i.e. the human skin, is subject to constant changes and is strongly dependent on the impact of environmental conditions. This means that the physical well-being of a person depends primarily on the temperature of the body's interior.

With regard to the surrounding environment, the thermal comfort understood as a thermal balance with the environment is important, i.e. the balance between the amount of heat produced by the body and the amount of heat lost to the environment. The zone of thermal comfort, in which a person feels good in normobaric conditions is within the range of $29-31^{\circ} \mathrm{C}$ [1]. Therefore, any disruption in the stability of temperature and its upward or downward deviation causes a disturbance of homeostasis, and thus the organism's ability to maintain the parameters of a stable internal environment is also impacted. At the same time defensive mechanisms are activated. It may be concluded that as a result of significant temperature variations the human body is subjected to a great deal of stress.

A diver moving in the water is primarily subject to the effect of cold water on his organism, which is a strong stressful stimulus. Long-term stays under water can cause the body to overcool. The consequence of this condition is hypothermia, i.e. primarily a reduction of body core temperature. This should be understood as an occurrence of a situation where the amount of heat produced by the diver's body is insufficient to cover its losses in water. Overcooling during diving activities leads to a higher probability of development of decompression sickness and other diving diseases. Lowering of the core body temperature below $30^{\circ} \mathrm{C}$ causes loss of consciousness due to hypoxia, which in certain cases can lead to drowning [3].

The mechanisms that lead to the cooling down of the body are mainly conduction and convection. The loss of heat to the surrounding environment mainly happens through the skin, whose area in an adult human reaches $1.8 \mathrm{~m} 2$. In hyperbaric conditions, due to the increased density of respiratory gases and physical and chemical properties of breathing mixtures, convection in particular intensifies the effect of reduction of the diver's body temperature [3]. The turbulence of the water around the diver, resulting from his physical activity as well as the high thermal conductivity of the water, also have a significant influence. To a lesser extent, heat loss occurs through the airways, whereas radiation is practically irrelevant.

The thermal condition of the diver affects the rate of absorption and elimination of inert gas. Under certain conditions, it may be conducive to an occurrence of decompression sickness (DCS). It was observed that divers staying at a certain depth (on the bottom) and maintaining heat in the organism, absorb more inert gas than divers feeling cold. This is due to vascoconstriction as a result of coldness, which reduces the absorption of inert gas. However, the same divers during the ascent and decompression stops release it faster than hypthermic divers [4]. The solubility of gases in the body is inversely proportional to the temperature [5].

\section{THE EFFECT OF LOW TEMPERATURES ON THE DIVING TECHNIQUE}

Low water temperatures affect the technical and essential characteristics of the diving technique. From this point of view the elements which are mainly susceptible to the effect of cold water include:

a) diving suits, 
b) breathing apparatuses.

Diving suits constitute an element of personal equipment of each diver. Among them we find:

a) wet suits,

b) dry suits of different volumes with passive thermal protection in the form of personal underwear and/or undersuit, optionally also vests and electrically heated undersuits,

c) suits with active thermal protection in the form a hot-water circuit heating system,

d) personal underwear.

Each of these groups has its advantages and disadvantages and should be precisely selected for specific diving conditions. Properly used clothing will have a significant impact on the heat balance of the diver. The heat exchange between the water and the diver takes place primarily by way of convection and conduction. The insulation created between the diver's body and the cold water or air environment will ensure proper blood supply to the body. It is important to maintain proper thermal protection of the limbs, both legs and arms as they are exposed to a faster lowering of the temperature than the diver's torso.

This leads to a radical decrease in blood circulation in these parts of the body and an increased feeling of coldness. A particularly important group of clothing is such that protects divers during diving exposures at medium and great depths as well as clothing dedicated to saturated dives with relatively long periods of stay in cold water. This phenomenon is supposed to be prevented by diving suits of various constructions. The assessment of their usability is carried out, inter alia, based on PN-EN 14225-1, PN-EN 14225-2 and PN-EN 14225-3 standards. One of the required tests is the test for the storage of suits at a low temperature and the performance of tests in conditions reflecting an actual stay in cold water with the assessment of their thermal efficiency.
The diving respiratory equipment is sensitive to the low temperatures of water and air. The open-circuit apparatuses supplied with compressed air are particularly susceptible to the effects of cold water. This is due to their relatively simple construction and mode of operation as compared to devices with semi-closed and closed circulation of the breathing gas, in which mainly breathing mixtures with helium content are used.

Their use in low temperature waters creates conditions for freezing. Particularly susceptible to this effect are the regulators consisting of a pressure reducer (1st stage) connected with a single hose to the breathing apparatus (2nd stage). These components may freeze as a result of the expansion and throttling process, known as the Joule-Thompson expansion or temperature throttling effect. It is characteristic for real gas flows.

The air exhaled by the diver is characterised, among others, by humidity whose temperature quickly decreases to negative values and transforms into ice crystals depositing on the inner surfaces of the 2nd stage. This is facilitated by the relatively high gas velocity in the flow system and the cyclically occurring pressure differences. It is not without significance that oxygen is a gas that increases the effect of the temperature drop. Therefore, exposures using nitrox breathing mixtures create a greater risk of freezing of the regulator as compared to when the diving cylinders are filled with air.

Open-circuit breathing apparatus with air used as the breathing mix are tested for compliance with the PN-EN 250 standard. They are tested, inter alia, on resistance to low temperatures and freezing. Depending on the susceptibility to this phenomenon, demand valves/regulators are certified for use in cold water, i.e. below $10^{\circ} \mathrm{C}$ or for operation above this temperature.

Fig. 1 demonstrates the effect of freezing of components of an open-cirucit diving apparatus supplied with air. a)

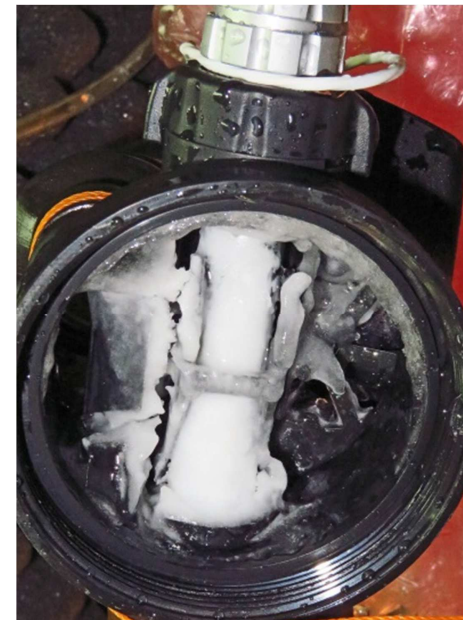

b)

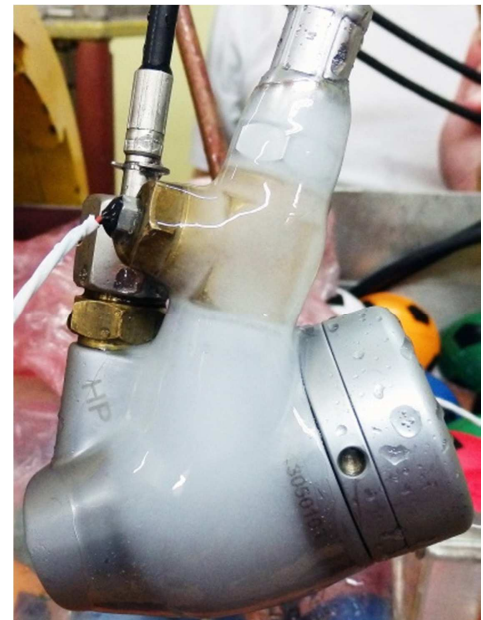

c)

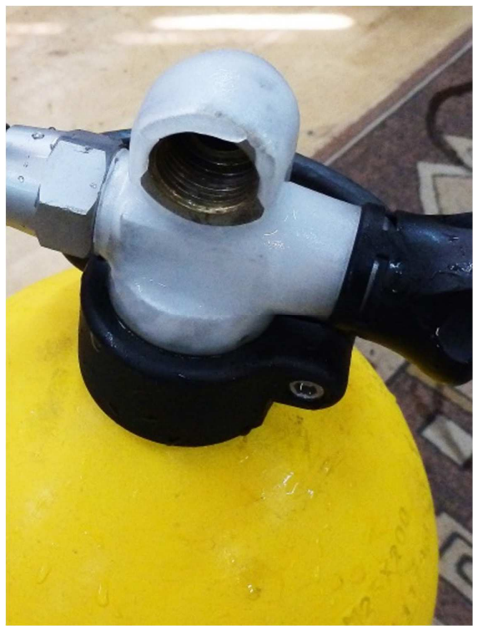

Fig. 1 The effect of freezing of components of an open-circuit diving apparatus supplied with air: a) the inside of the 2 nd stage of a diver's regulator, b) the $1^{\text {st }}$ stage of a diver's regulator, c) the cross-flow valve of the cylinder. 
The studies on the impact of low temperatures on the said areas can be carried out in simulators both with or without the participation of humans. Regardless of the assumptions and requirements of experimental programmes or testing procedures, they must ensure stable performance parameters, including the provision of water cooling systems. This is aimed at obtaining conditions mimicking the water environment in order to make it possible to understand the impact of adverse temperature conditions on the diver's body and develop methods for their effective prevention. This goal was set and implemented in the DGKN-120 diving simulator of the Department of Underwater Works Technology.

\section{TECHNICAL AND OPERATIONAL ANALYSIS}

\section{OF THE OLD COOLING SYSTEM}

A technical and operational analysis of the old water-cooling system in the basin of the "Kobuz" chamber, used in the 1990 s was carried out in order to draw conclusions regarding its construction, structural solutions, assessment of technical and operational properties, efficiency of operation and economics of its exploitation. These activities were to prevent mistakes and indicate the directions of design works to build a system based on relatively new technical and material solutions. Based on the experience in the operation of the old system, it was observed that:

a) the disassembled system was a technically inefficient construction built on the basis of copper materials and brass alloys (pipelines, joints), which are no longer in use,

b) the water flow systems in the heat exchanger "stiffened" as a result of using pipelines and connectors with larger diameters and thicker and connections performed by use of the soldering and welding technology, c) the heat exchanger installed in the chamber's basin was characterised by a relatively large weight and low cooling efficiency, which resulted in it taking a very long time to lower the temperature of approx. 5 tons of water mass stored in the pool to the required value; too small and poorly developed surface of the heat exchanger impeded the process of water cooling - we may speak of a passive nature of the system's operation,

d) there was no forced circulation inside the basin to mix temperature-varying masses of water, and its movement was only caused by the phenomenon of convection,

e) the low efficiency of maintaining a stable temperature of cooled water in the pool, resulted, among others, from the lack of thermal insulation of both the swimming pool part and the circulation pipelines; causing a heat exchange with the environment and condensation of water vapour on the outer surface of the decompression chamber within the water basin,

f) the operated system was characterised by a high energy consumption in relation to the power source, which had low cooling power and low technical and operational parameters in order to effectively lower and maintain the required water temperature,

g) the absence of a pool water filtration system for the purpose of filtering and preventing the reproduction of harmful bacteria, directly threatening the divers in the water.

Fig. 2 illustrates the old water-cooling system of the „Kobuz” decompression chamber.

a)
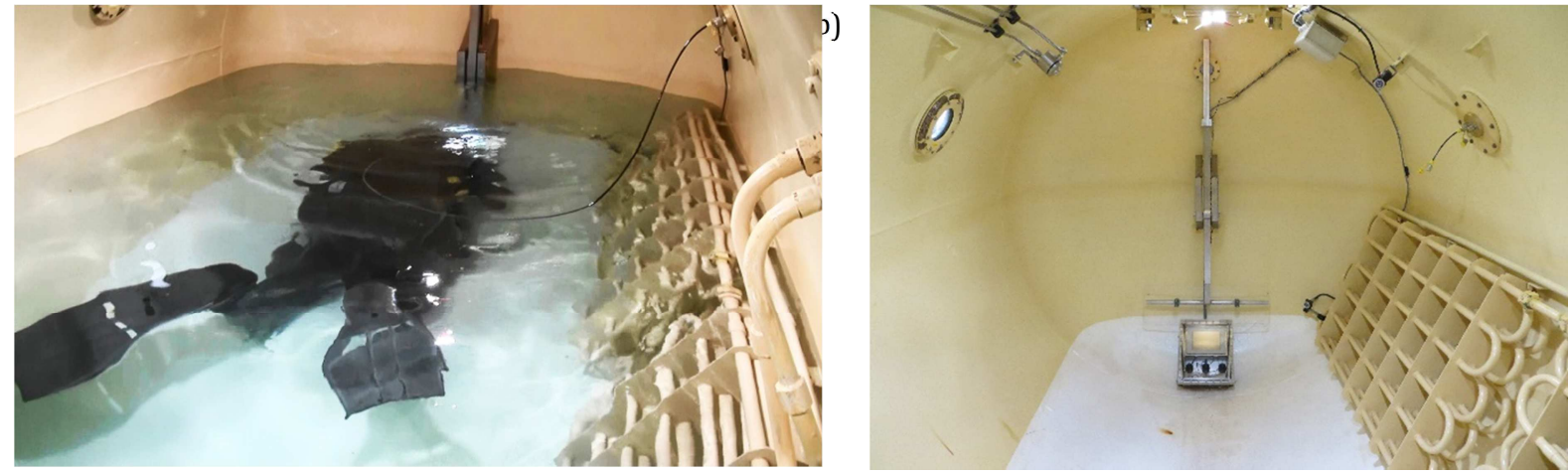

Fig. 2 The basin of the „Kobuz" decompression chamber prior to the installation of a new cooling system: a) filled with water during an experiment, b) without water.

THE NEW WATER-COOLING SYSTEM IN THE BASIN OF THE 'KOBUZ' DECOMPRESSION CHAMBER

A part of the ongoing project and works aimed at preparing the DGKN-120 hyperbaric simulator for experiments involved the designing of a new watercooling system in the basin of the "Kobuz" decompression chamber. The project developed the concept of the system's operation, defined the location of system components in relation to particular installations, and their placement within the department's facilities.
Implementation devices have also been selected to ensure adequate efficiency and stability in maintaining the pool's temperature at the required level. Fig. 3 presents the functional scheme of the water-cooling system in the „Kobuz” chamber.

The basis for the design of the water-cooling system in the pool of the "Kobuz" decompression chamber was constituted by the output parameters summarised in Table No. 1. 


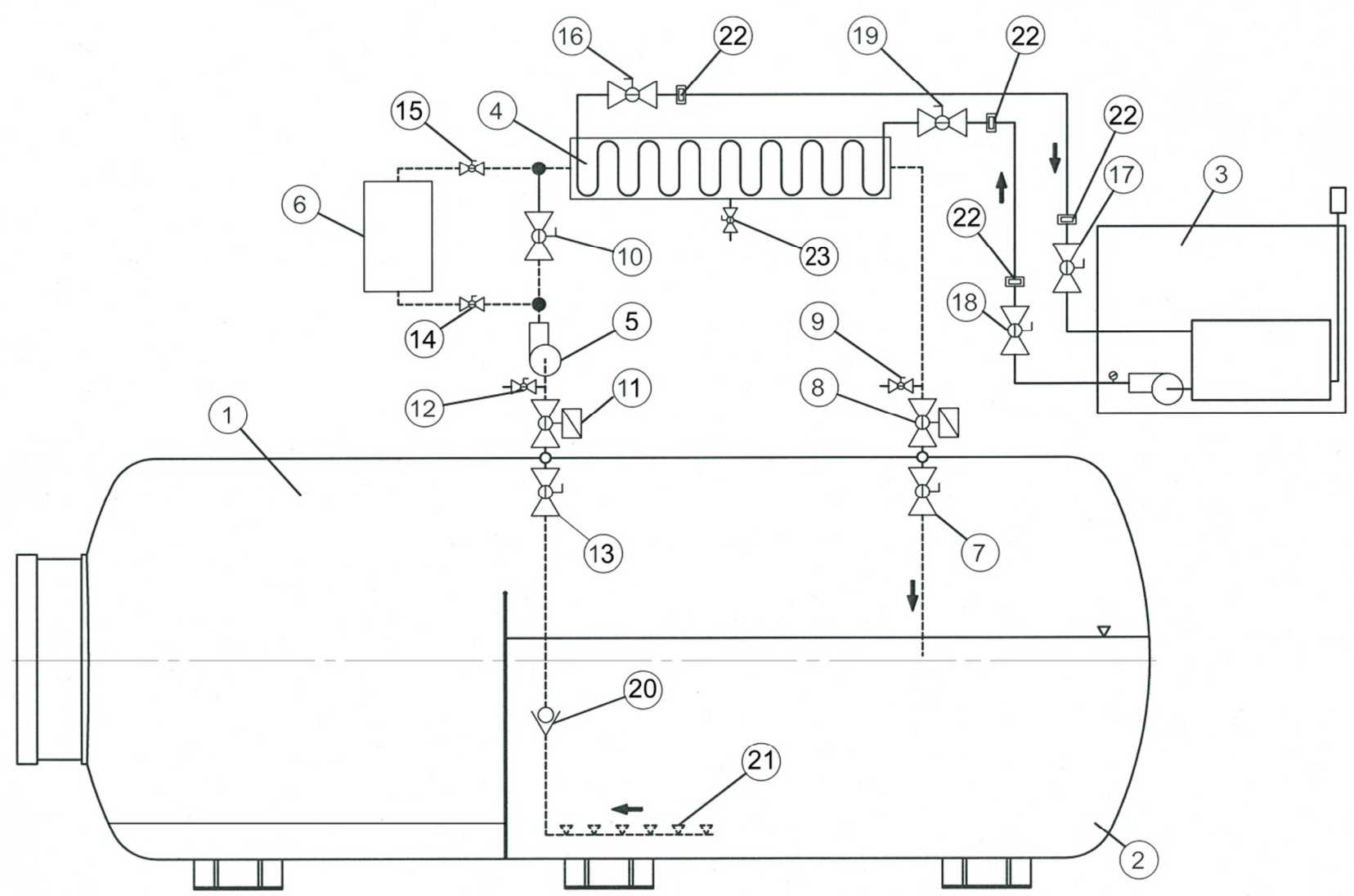

Fig. 3 The conceptual design of the water cooling system for the „Kobuz” decompression chamber (fig. M.Palczewski-Haska)

1 - „Kobuz" decompression chamber; 2 - water pool; 3 - cooling aggregate TAE evo Tech 081/P3; 4 - heat exchanger JAD XK 5.38; 5 - GPD circulator pump; 6 - FSE water filter; 7,13 - shut-off ball valve; 8,11 - pneumatically controlled shut-off ball valve; $9,12,23$ - vent valve; 10 - shut-off ball valve; 14 15 - water filter shut-off ball valve; $16,17,18,19$ - cooling installation shut-off ball valve; 20 - non-return valve of suction installation; 21 - pipe with holes for sucking up water from the pool; 22 - joints of the cooling installation pipes.

The assumed operational parameters for the water-cooling system of the „Kobuz" decompression chamber.

\begin{tabular}{clc}
\hline No. & \multicolumn{1}{c}{ Specification } & Value \\
\hline 1. & Water mass to be cooled in the pool of the „Kobuz” decompression chamber & $\sim 5.0$ tones \\
\hline 2. & Output temperature of pool water (determined experimentally) & $\sim+13.0^{\circ} \mathrm{C}$ \\
\hline 3. & Required minimum temperature of water in the pool & $+2.0^{\circ} \mathrm{C}$ \\
\hline 4. & Required calculated stream of heat to be drained $+20 \%$ loss & $\sim 74.0 \mathrm{~kW}$ \\
\hline
\end{tabular}

The new water-cooling system in the pool of the „Kobuz” decompression chamber was divided into two parts:

Internal part consisting of the following elements:

- Intake manifold for cooled water from heat exchanger into the pool;

- Suction manifold for water from the pool into the heat exchanger;

- $\quad$ Shut-off ball valves;

- Cover with passages through the decompression chamber body, connecting both parts of the system.

External part consisting of the following elements and devices:
- $\quad$ Centrifugal one-stage circulation pump forcing water sucked from the pool through a heat exchanger with three-stage efficiency control;

- Heat exchanger;

- Water filter;

- Flexible pipelines connected by connectors and shut-off ball valves;

- $\quad$ Refrigerating unit circulating the refrigerant to the heat exchanger set in a portable container outside the main room of the hyperbaric simulator.

- $\quad$ Cut-off ball valves connected to passages in the cover installed in the body of the decompression chamber; 


\section{WATER INSTALLATION CONSTRUCTION INSIDE THE 'KOBUZ' DECOMPRESSION CHAMBER}

The purpose of the internal installation of the cooling system is to supply and drain water from the pool to the heat exchanger located outside the decompression chamber. Water circulation is forced by a single-stage rotodynamic water pump for potable water with a threestage variable capacity not exceeding $10.5 \mathrm{~m} 3 / \mathrm{h}$. The internal water installation, as well as its part located outside the chamber, operates under pressure with a maximum value not exceeding $1.2 \mathrm{MPa}$ (12 bar), which results from the working parameters of the hyperbaric simulator DGKN-120.

The entire installation was performed from stainless steel valves, pipes and fittings with a nominal diameter of 2". Pipe fragments were fitted to the inner bilge of the decompression chamber, and their endings were placed near the bottom of the tank at the opposite ends of the water pool. This is an active solution as it ensures forced water movement in the pool. Continuous mixing allowed to achieve a practically homogeneous temperature distribution across the entire water mass. The possibility to change the water flow rate due to three available settings of the force pump, ensures a relatively quick reduction of the water temperature in the cooling system and maintains it at the required level.

Fig. 4 illustrates the external and internal parts of the water circulation system between the pool and the heat exchanger. a)

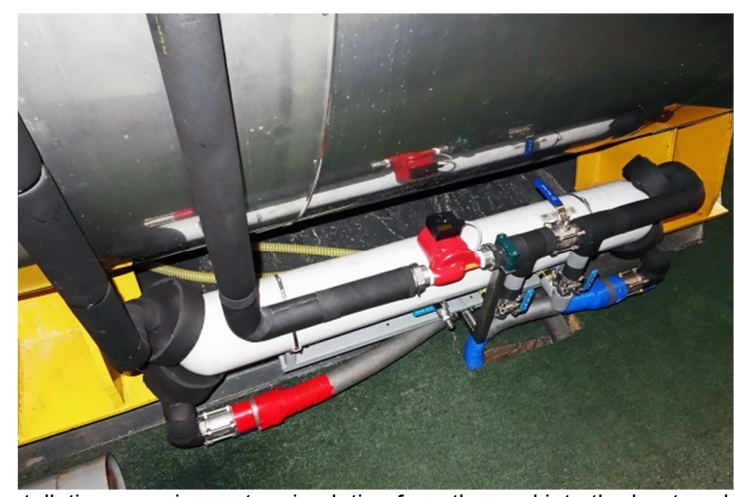

b)

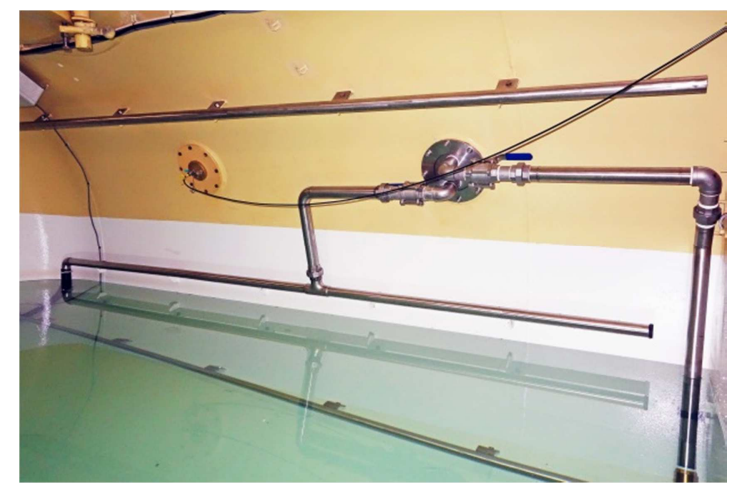

Fig. 4 Installation ensuring water circulation from the pool into the heat exchanger: a) external part, b) internal part.

\section{WATER INSTALLATION CONSTRUCTION OUTSIDE THE 'KOBUZ" DECOMPRESSION CHAMBER}

The cooling of water taken from the pool is performed in a pressurised heat exchanger mounted outside the decompression chamber. It is placed close to its jacket in such a way as to ensure that the pipelines producing the circulation are as short as possible. This ensures a reduction in the heat loss between the outside environment and the installation. The arrangement of the pipes inside the chamber and the external part of the flow installation is adapted to the operation under compressed pressure in the gas chamber. The pipelines were covered with normal foam thermal insulation.

Based on the calculations carried out and a market survey, a heat exchanger with a compact design was selected. It ensures turbulent flow, which guarantees good system performance, including the rate of cooling the water to the required temperature values.

Table No. 2 summarises the basic technical and operational parameters of the heat exchanger used in the cooling system of the "Kobuz" decompression chamber. Fig. 5 presents basic measurements of the heat exchanger.

A refrigerating unit was selected to operate in conjunction with the heat exchanger, whose basic operating parameters are summarised in Table 3. It was placed outside the DGKN-120 hyperbaric simulator in a portable transport container. An air intake system for the unit's ventilation system was installed with flexible pipelines connected to it, which ensure the circulation of the refrigerant to the heat exchanger and its return. This circuit is an intermediate system and does not have direct contact with the water filling the pool. The pipelines were protected against heat loss by applying foam thermal insulation.

Table No. 3 summarises the basic operating parameters of the refrigerating unit. 
Basic technical and operating parameters of the heat exchanger.

\begin{tabular}{cll}
\hline No. & \multicolumn{1}{c}{ Specification } & \multicolumn{1}{c}{ Characteristics } \\
\hline 1. & Manufacturer & SECESPOL \\
\hline 2. & Type of exchanger & shell-and-tube \\
\hline 3. & Type of operation / heat exchange & flow / counter-flow \\
\hline 4. & Model & JAD XK 5.38 (JAD XK FF.STA.SS) \\
\hline 5. & Material: shell / tubes & steel 304L / steel 321 \\
\hline 6. & Operational pressure & 16 bar \\
\hline 7. & Heat exchange surface & $4 \mathrm{~m}^{2}$ \\
\hline 8. & Capacity : shell / tubes & $11.2 / 6.6 \mathrm{dm}^{3}$ \\
\hline 9. & Max. water flow : shell / tubes & $19.0 / 7.0 \mathrm{~m}^{3} / \mathrm{h}$ \\
\hline 10. & Max. operating temperature & $203^{\circ} \mathrm{C}$ \\
\hline 13. & Shell diameter $-\varnothing$ Dz & $\emptyset 139.7$ \\
\hline 14. & External thermal insulation & polyurethane foam \\
\hline
\end{tabular}

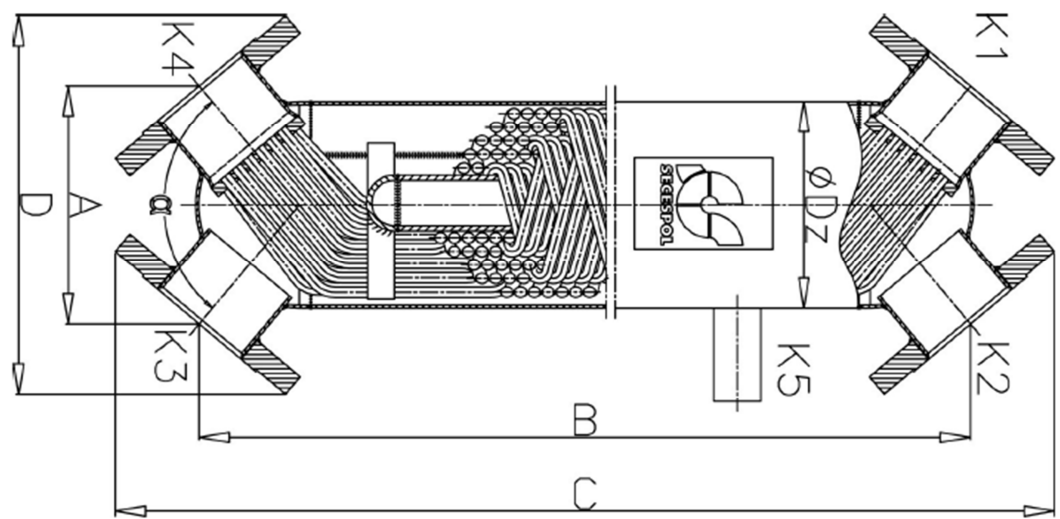

Fig. 5 Basic dimensions of the JAD XK 5.38 heat exchanger used in the water cooling system of the "Kobuz" decompression chamber" (advertising material).

Basic technical and operating parameters of the refrigerating unit

\begin{tabular}{|c|l|l|}
\hline L.p. & \multicolumn{1}{|c|}{ Specification } & \multicolumn{1}{c|}{ Characteristics } \\
\hline 1. & Manufacturer & M.T.A. S.p.A. Italy \\
\hline 2. & Model / Version & TAEevo TECH 081 / STD \\
\hline 3. & Heat exchanger & finned submersible coil \\
\hline 4. & Refrigerant & R410A \\
\hline 5. & Glycol type & EthyleneGlycol \\
\hline 6. & Percentage glycol content & $\geq 19 \%$ \\
\hline 7. & Cooling capacity & $18 \mathrm{~kW}$ \\
\hline 8. & $\begin{array}{l}\text { Quantity of water flowing through the } \\
\text { evaporator }\end{array}$ & $3.26 \mathrm{~m}^{3} / \mathrm{h}$ \\
\hline 9. & Electric power & $8.03 \mathrm{~kW}$ \\
\hline 10. & Available pressure range & $2.78 \mathrm{bar}$ \\
\hline
\end{tabular}


Fig. 6 presents the placement of the refrigerating unit in the transport container.

\section{THERMAL INSULATION OF THE POOL PART IN THE 'KOBUZ" DECOMPRESSION CHAMBER}

In order to ensure and maintain the best technical parameters of the pool water cooling system during operation, thermal insulation was applied to the outer part of the "Kobuz" decompression chamber and the internal vertical wall. Properly selected thickness of polyurethane foam along with protection in the form of a stainless-steel sheet is used to prevent significant losses of heat during its use. a)

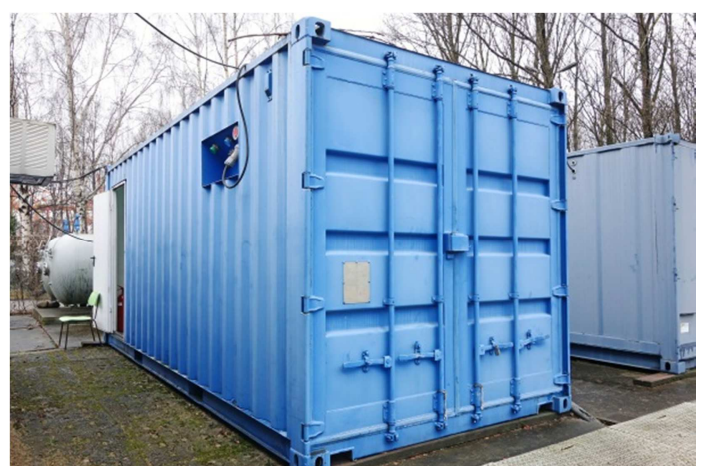

b)

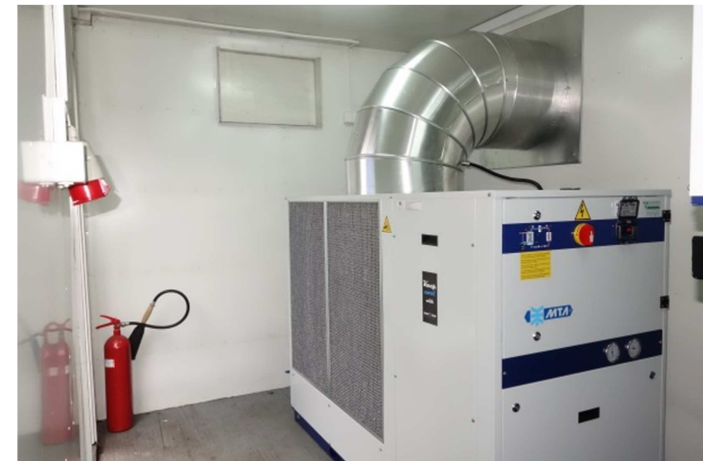

Rys. 6 The placement of the refrigerating unit in the transport container: a) transport container, b) refrigerating unit.

This resulted in a significant increase in the stability of maintaining the required temperature of water in the pool and power consumption of the entire cooling system.

Fig. 7 shows the „Kobuz” decompression chamber before and after the installation of thermal insulation of the pool area. a)

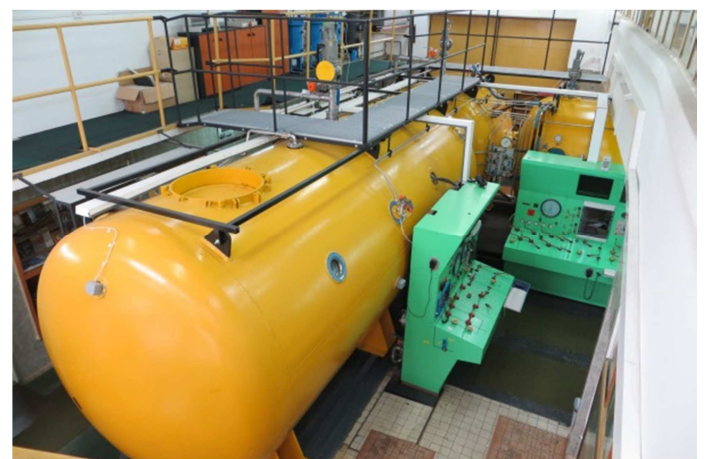

b)

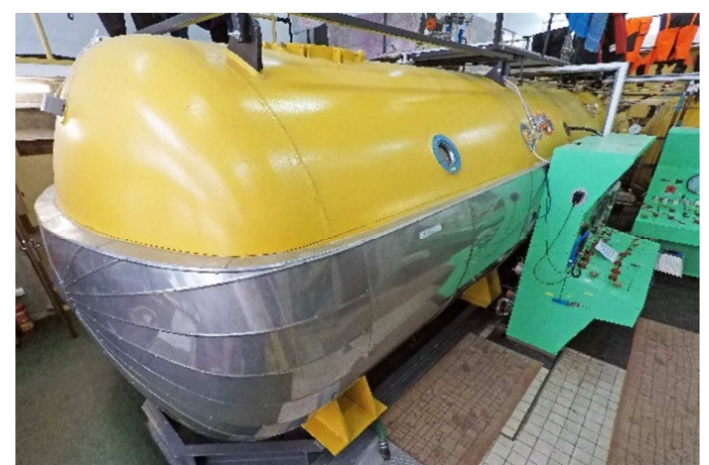

Fig. 7 The effect of installation works on the thermal insulation in the pool part of the „Kobuz” decompression chamber: a) chamber before the provision of insulation, b) chamber after the provision of insulation.

\section{WATER FILTER INSTALLATION IN THE}

\section{POOL OF THE “KOBUZ" DECOMPRESSION} CHAMBER

In the water-cooling system in the pool of the "Kobuz" decompression chamber, a filter was installed that allows cleaning of mechanical and biological impurities. The periodic purification process allows the water to be kept clean for a longer period of time. This is an important element of decreasing the water consumption, resulting from the reduction in the number of times it is changed. The lack of this device in the old installation forced frequent water changes in order to maintain sanitary and epidemiological requirements. Divers taking part in experiments and trainings requiring a stay in the simulated water environment were most exposed to the effects of biological contamination.

The basic cleaning medium is a sand layer of proper granulation poured into the tank of the device. The 
filter is installed in parallel to an external installation ensuring cooling and circulation of the pool water. The device is not adapted to work under pressure, so it can also be used after completion of the diving exposures. The flow of water through the filter cartridge placed in the tank is forced by the circulating pump installed in the system. The connection to the internal flow system is performed by means of ordinary, crimped flexible hoses.

\section{CONCLUSIONS}

The implementation of works resulted in a new cooling system characterised by:

- A relatively good cooling efficiency of approx. 5 tons of water in the pool of the decompression chamber, ensuring the achievement of temperatures in the range of $2-4{ }^{\circ} \mathrm{C}$ in $4-5$ hours;

- The use of forced, active water circulation, by means of a properly selected pump, which significantly shortens the time required for reaching the required temperature due to continuous mixing;

- $\quad$ Reduced dimensions of the cooling system as a result of the use of a compact and efficient heat exchanger;

a)

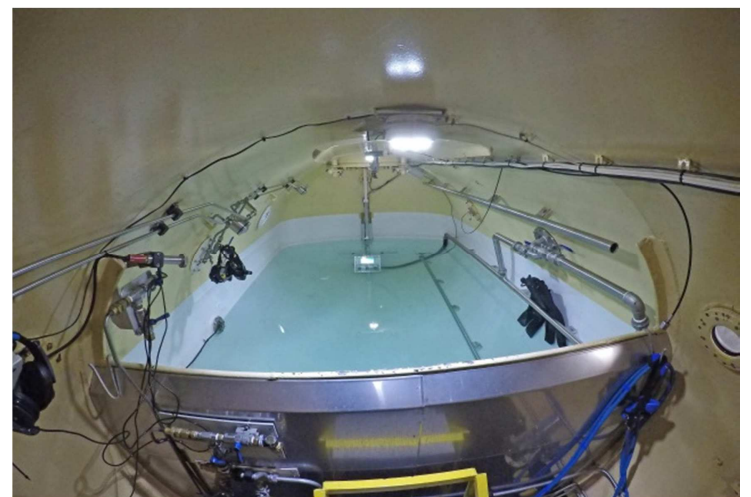

- The use of a modern refrigerating unit that provides for a specific range of adjustment of its operation, and thus the selection of appropriate parameters for specific needs. Adaptation of the cooling capacity of the unit and heat exchanger enables full utilisation of their technical and operational properties;

- Increasing the usable volume of the pool as a result of removing the old heat exchanger construction, and installing a new one mostly located outside the decompression chamber;

- Maintaining a stable temperature in the pool at the required level due to the performance of partial thermal insulation of the external area of the chamber, which significantly reduced the heat loss, as well as insulating of all pipelines of the cooling system;

1. Increased sanitary-epidemiological safety during diving exposures as a result of the use of a pool water purification filter for mechanical and biological impurities;

2. A significantly higher energy saving as compared to the old cooling system, as well as a reduction in the pool water exchange rates.

Fig. 8 presents the water pool of the decompression chamber following the completion of works as well as during an experimental exposure.

b)

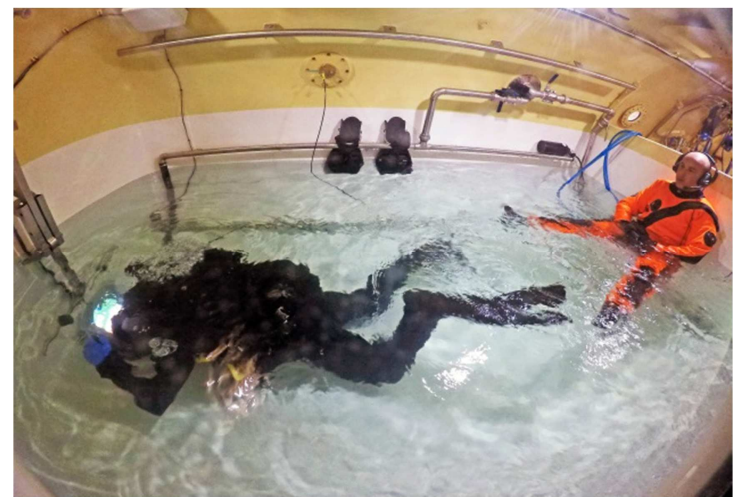

Fig. 8 The water pool of the "Kobuz” decompression chamber following the completion of works: a) filled with water, b) during an experimental diving exposure.

\section{REFERENCES}

1. [23.05.2018] "Wymiana cieplna u człowieka" [Heat exchange in a man] www.idawpolsce.pl/uploads/do_pobrania/Prezentacjafizjologia\%20nurkowania_maj.2012.pdf;

2. [23.05.2018] "Termoregulacja organizmu człowieka i obciążenie termiczne" [Thermoregulation and thermal load of human organism] Prof. $M$. Krause, Ph.D., M.D. http://ergonomia.ioz.pwr.wroc.pl/download/termoregulacja-teoria.pdf;

3. J. Krzyżak - „Medicine for divers. Physiopathology of diving” Publ. "KOOPgraf" s.C., AWF Poznań 1998;

4. US Navy Diving Manual rev. 7 2016;

5. [23.05.2018] "Wpływ bilansu cieplnego nurka na ryzyko choroby dekompresyjnej" [The effect of diver's thermal balance on the risk of an occurrence of decompression sickness] http://www.atlantis.vizz.pl/Wplyw\%20bilansu\%20cieplnego\%20nurka.html.

\section{dr inż. Zbigniew Talaśka}

Akademia Marynarki Wojennej im. Bohaterów Westerplatte

81-103 Gdynia 3 ul. Śmidowicza 69

Zakład Technologii Prac Podwodnych

tel. +586262746 , fax. +586253882

e-mail : zbigniew_talaska@wp.pl 